\title{
Advanced glycation end products facilitate the proliferation and reduce early apoptosis of cardiac microvascular endothelial cells via PKC $\beta$ signaling pathway: Insight from diabetic cardiomyopathy
}

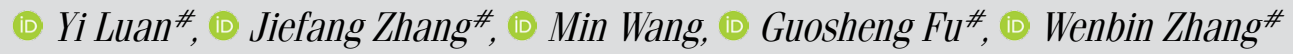 \\ Department of Cardiology, Key Laboratory of Cardiovascular Intervention and Regenerative Medicine, \\ Sir Run Run Shaw Hospital, College of Medicine, Zhejiang University; Zhejiang-P.R. China
}

\section{ABSTRACT}

Objective: To investigate the effects of advanced glycation end products (AGEs) on the proliferation and apoptosis of cardiac microvascular endothelial cells (CMECs) in rats and their underlying signaling pathway.

Methods: CMECs were isolated from Sprague-Dawley rats. We first examined the effects of AGEs on the proliferation and apoptosis of CMECs and then tested whether protein kinase $C$ (PKC) $\beta$ blockers could counteract the effects of AGEs. The PKC agonists phorbol 12-myristate 13-acetate (PMA) and PKC $\beta$ blockers were also used to verify whether PKC could act independently on CMECs. The receptor for AGEs (RAGE)-small interfering RNA (siRNA) transfection was used to verify the effect of AGEs on PKC. Following the above steps, we explained whether AGEs regulated the CMEC proliferation and early apoptosis through the $\mathrm{PKC} \beta$ signaling pathway. Proliferation of CMECs was detected using the Cell Counting Kit-8 (CCK-8) assay, and early apoptosis was determined using the Annexin V- Fluorescein Isothiocyanate (FITC)/propidium iodide (PI) double staining. Expression of proliferation and apoptosis-related proteins and PKC phosphorylation were determined by western blotting analysis. Cell cycle distributions were assayed using a BD FACSCalibur cell-sorting system.

Results: AGEs facilitated the proliferation of CMECs, upregulated phosphorylated extracellular signal regulated kinase ( $p$-ERK), and accelerated the entry of cells from $\mathrm{G} 1$ phase to the $\mathrm{S}+\mathrm{G} 2 / \mathrm{M}$ phase, which was consistent with the upregulated cyclin D1 by AGEs. AGEs inhibited early apoptosis of CMECs by increasing the expression of survivin and decreasing the expression of cleaved-caspase3. All these effects can be reversed by PKC $\beta 1 / 2$ inhibitors. In addition, AGE upregulated the RAGE expression and phosphorylation of PKC $\beta 1 / 2$ in CMECs, while the inhibition of RAGE reversed the phosphorylation, as well as the effects of AGEs on proliferation and apoptosis in CMECs.

Conclusion: The study indicated that AGEs facilitated the proliferation and reduced early apoptosis of CMECs via the PKC $\beta$ signaling pathway. (Anatol J Cardiol 2020; 23: 141-50)

Keywords: advanced glycation end products, cardiac microvascular endothelial cells, diabetic cardiomyopathy, protein kinase C

\section{Introduction}

Diabetic cardiomyopathy (DCM) is one of the most common microvascular complications of diabetes (1-3). For patients with DCM, early clinical cardiac function can be intact, left ventricular diastolic dysfunction and cardiac hypertrophy begin to appear in the middle stage, and systolic dysfunction occurs last (4, 5). Monolayer endothelial cells, as a component of the myocardial microvascular wall, play an important role in regulating of the microvascular function. The development of many cardiovascular diseases, including diabetic heart disease, is closely related to the damage of cardiac microvascular endothelial cells (CMECs) $(6,7)$.

Increasing evidence has suggested that the accumulation of advanced glycation end products (AGEs) is involved in diabetesrelated diseases $(5,8)$. AGEs can change the structure of proteins, cross-link collagen molecules, increase the stiffness of diabetic hearts, and impair cardiac function $(8,9)$. Engagement of the receptor for AGEs (RAGE) with AGEs can elicit oxidative stress and subsequently evoke proliferation, inflammation, and fibrosis in a variety of cells (8). Therefore, blocking the AGEs-RAGE system is recognized as an important approach in the future treatment of

"Equal contribution.

Address for correspondence: Wenbin Zhang, MD, Department of Cardiology, Key Laboratory of Cardiovascular Intervention and Regenerative Medicine, Sir Run Run Shaw Hospital, College of Medicine, Zhejiang University; 3 East Qingchun Road, Hangzhou, 310016, Zhejiang-P.R. China

Phone: +86-0571-8600-6248 E-mail: 3313011@zju.edu.cn

Accepted Date: 31.10.2019 Available Online Date: 13.02.2020

(C)Copyright 2020 by Turkish Society of Cardiology - Available online at www.anatoljcardiol.com DOl:10.14744/AnatolJCardiol.2019.21504 
chronic diabetic complications. Previous studies examining the AGEs-RAGE system have focused on diabetic macroangiopathy, while now the AGEs-RAGE axis has been found to have an effect on diabetic microangiopathy (10).

In addition, protein kinase C (PKC) activation can also lead to diabetic microvascular complications (11). Among various PKC isoforms, $\beta$ isoform appears to be preferentially activated in the vascular system of diabetic animals (12). Studies have shown that $P K C \beta$ is associated with cardiac microvascular ischemia-reperfusion injury in diabetic rats (13), and PKC activation contributes to the microvascular barrier dysfunction in the heart at an early stage of diabetes (14). However, whether AGEs can regulate the CMEC function through the $\mathrm{PKC} \beta$ signaling pathway in diabetes is still unknown.

Therefore, we explored this scientific issue based on the phenotype of CMECs and tried to provide new insights into the pathogenesis of diabetic cardiomyopathy.

\section{Methods}

\section{Animal and cell culture}

CMECs were isolated and cultured in Dulbecco's minimum essential medium (DMEM), supplemented with $20 \%$ fetal bovine serum (FBS) (10). Briefly, the left ventricles of male Sprague-Dawley rats (Shrek, Shanghai) (200-250 g) were harvested and minced into $1 \mathrm{~mm}^{3}$ small pieces after the removal of the endocardial endothelium and epicardial coronaries. The remaining tissue was then minced in phosphate buffered saline (PBS) and incubated in $0.2 \%$ collagenase (Type II; Sigma Aldrich, St. Louis, MO, USA) for 10 min, followed by $0.2 \%$ trypsin (Sigma Aldrich, St. Louis, MO, USA) for another 6 min at $37^{\circ} \mathrm{C}$ in a water bath. After centrifugation, the cells were resuspended in DMEM supplemented with $20 \%$ FBS and plated on $10 \mathrm{~cm}$ dishes. All institutional and national guidelines for the care and use of laboratory animals were followed. The CMECs were positively identified by CD31 surface antigen expression using immunofluorescence staining and flow cytometry (Becton Dickinson, USA). Afterwards, the CMECs were cultured in different mediums including AGE albumin and bovine serum albumin (BSA) $(50 \mathrm{mg} / \mathrm{mL})$. CGP53353 (Sigma, USA) was used as a PKC $\beta 1$ inhibitor $(6.0 \mathrm{nmol} / \mathrm{mL})(15)$ and PKC $\beta 2$ inhibitor $(0.9 \mathrm{nmol} /$ $\mathrm{mL})(16)$, and phorbol 12-myristate 13-acetate (PMA) $(50 \mathrm{ng} / \mathrm{mL})$ (Sigma, USA) was used as a PKC agonist.

AGE-modified albumin (AGE albumin) was synthesized under sterile conditions by incubating BSA (low endotoxin, Merck) with $0.5 \mathrm{M} \mathrm{D}$-glucose in $100 \mathrm{mM}$ PBS, as previously described (10), and then, the mixture was fully dialyzed against PBS to remove unbound glucose. BSA incubated without glucose under the same conditions was used as the negative control in all experiments.

\section{Proliferation assay}

The CMECs proliferation was detected using the Cell Counting Kit-8 (CCK-8) assay. Briefly, the CMECs were digested with trypsin and then cultured in serum-free medium in a 96-well cul- ture plate $(200 \mu \mathrm{L} /$ well). The four groups were identified as the control, AGEs, AGEs+PKC $\beta 1$ inhibitor, and AGEs+PKC $\beta 2$ inhibitor. CCK-8 solution was added to each well, and the cells were incubated for $0.5,1,2$, or 4 hours, and the absorbance (A) at $450 \mathrm{~nm}$ was measured by using an automatic multi-well spectrophotometer (Bio-Rad, Richmond, CA, USA).

\section{Apoptosis assay}

An annexin V kit (BioVision Inc. USA) was used to determine the percentage of cells undergoing apoptosis. Briefly, the CMECs were harvested after 24-hour treatments. Approximately, 15.000 cells were detected for each sample. Then, the cells were trypsinized gently and resuspended with binding buffer, and they were treated with $5 \mu \mathrm{L}$ annexin V-Fluorescein Isothiocyanate (FITC) and $5 \mu \mathrm{L}$ propidium iodide (PI). After the incubation for 5 min on ice, each sample was analyzed immediately using the FACSCalibur flow cytometer (Becton Dickinson, USA).

\section{Cell cycle distribution assay}

DNA distributions throughout the cell cycle were assayed using a BD FACSCalibur cell-sorting system (17). The cells were placed into six-well plates and divided into several groups. After counting, $10^{6}$ cells $/ \mathrm{mL}$ were washed with PBS and fixed in $70 \%$ ethanol overnight at $4^{\circ} \mathrm{C}$. The cells were centrifuged, washed again with PBS, and then stained for DNA content $(1 \mathrm{mg} \mathrm{PI}$ and $25 \mathrm{mg}$ ribonuclease $A$ in $1 \mathrm{~mL}$ PBS) for $30 \mathrm{~min}$ at room temperature and promptly analyzed by flow cytometry.

\section{Western blotting analysis}

The procedures used were similar to those described previously, with slight modifications (18). Treated CMECs were scraped in the radio immunoprecipitation assay (RIPA) lysis buffer (Beyotime, Shanghai, China). The primary antibodies anti-RAGE, antiphosphorylated protein kinase $\mathrm{B} /$ extracellular signal regulated kinase (pAKT/ERK), and anti-caspase3 were purchased from Cell Signalling Technology (MA, USA). Anti-pPKC $\beta 1 / \beta 2$, anti-pPKCa, anti-survivin, and anti-glyceraldehyde-3-phosphate dehydrogenase (GAPDH) polyclonal antibodies were purchased from Santa Cruz Biotechnology (CA, USA). Anti-cyclin D1 and anti-cyclin B1 were purchased from Abcam (Cambridge, MA). The secondary antibodies conjugated to horseradish peroxidase were purchased from Cell Signalling Technology. The images were captured on an image reader LAS-4000 system (Fujifilm, Tokyo, Japan).

\section{Small interfering RNA (siRNA) transfection}

The RAGE siRNA target duplex sequences (Sense: 5'-CACAGCCAAUGUCCCUAAUTT-3', Antisense: 5'-AUUAGGGACAUUGGCUGUGTT-3') were synthesized by Thermo (CA, USA). In brief, CMECs were transferred into 24-well plates and cultured in DMEM supplemented with $20 \% \mathrm{FBS}$. After overnight growth, the cells were treated with $0.5 \mathrm{ml}$ Opti-MEM I (Invitrogen, Canada) with each well containing $50 \mathrm{nmol} / \mathrm{L}$ siRNA duplexes and $5 \mu \mathrm{L}$ Lipofectamine2000. 


\section{Statistical analysis}

All determinations were performed in triplicate, and experiments were repeated at least three times. The data were presented as the means \pm SEM. Analyses were conducted with SPSS 18.0, using the unpaired Student's t-test for comparisons between two groups and one-way analysis of variance for multiple comparisons. A p-value $<0.05$ was considered statistically significant.

\section{Results}

AGEs facilitated the CMECs proliferation, and the PKC activation promoted it independently

The proliferative activity of CMECs incubated in AGEs was evaluated. After treatment with AGEs for 0.5, 1, 2, and 4 hours, the proliferations of CMECs significantly increased for $240 \%$, $249 \%, 89 \%$, and $144 \%$, compared with the control group ( $p<0.05)$ (Fig. 1a). To elucidate the relationship between the PKC signaling pathway and AGEs with regard to their effects on CMECs, we further treated cells with a $\mathrm{PKC} \beta$ inhibitor (РKC $\beta 1$ inhibitor 6 $\mathrm{nmol} / \mathrm{mL}$ and $\mathrm{PKC} \beta 2$ inhibitor $0.9 \mathrm{nmol} / \mathrm{mL}$ ). The proliferations of CMECs induced by AGEs were decreased ( $<<0.05$ ) (Fig. 1a).

Furthermore, the phosphorylation of proliferation-related protein ERK was assessed by western blotting, and AGEs up- regulated phosphorylation of ERK by $55.7 \%(p<0.05)$ (Fig. $1 \mathrm{~b}$ and 1c). Both PKC $\beta 1$ and PKC $\beta 2$ inhibitor-treated cells downregulated the phosphorylation of ERK. In addition, AGEs had a similar impact on AKT phosphorylation (Fig. 1d).

As the cell cycle was closely related to proliferation, effects of AGEs on cell cycle distribution were examined. The percentage of AGEs-treated cells in $\mathrm{G} 1$ phase decreased from $78.5 \%$ to $54.1 \%(p<0.05)$, while cells in the $S+G 2 / M$ phase increased from $21.5 \%$ to $45.9 \%(p<0.05)$ (Fig. 1e), which suggested AGEs accelerated the entry of cells from $\mathrm{G} 1$ phase to the $\mathrm{S}+\mathrm{G} 2 / \mathrm{M}$ phase, thereby promoting DNA synthesis and cell proliferation. The percentage of $\mathrm{G} 1$ phase cells pretreated with the $\mathrm{PKC} \beta 1$ inhibitor $(6.0 \mathrm{nmol} / \mathrm{mL})$ and $\mathrm{PKC} \beta 2$ inhibitor $(0.9 \mathrm{nmol} / \mathrm{ml})$ increased from $54.1 \%$ to $71.8 \%$ and $60.3 \%(p<0.05)$, respectively, while the percentage of cells in the $\mathrm{S}+\mathrm{G} 2 / \mathrm{M}$ phase decreased from $45.9 \%$ to $28.2 \%$ and $39.7 \%$, respectively $(p<0.05$ ) (Fig. 1e). Thus, these results might demonstrate that the PKC $\beta$ inhibitor CGP53353 inhibited the effects of AGEs by arrest cells from G1 phase to the $\mathrm{S}+\mathrm{G} 2 / \mathrm{M}$ phase. We also assessed the role of cyclin $\mathrm{B} 1$ and cyclin $\mathrm{D} 1$ in the cell cycle of CMECs by western blotting and found that AGEs upregulated the expression of cyclin D1 by $88.3 \%(p<0.05)$, while no significant effect was observed on cyclin B1 ( $p>0.05)$ (Fig. 1f, $1 \mathrm{~g}$ and $1 \mathrm{~h}$ ). Both $\mathrm{PKC} \beta 1$ and $\mathrm{PKC} \beta 2$ inhibitor-treated cells downregulated expressions of cyclin D1 significantly. a

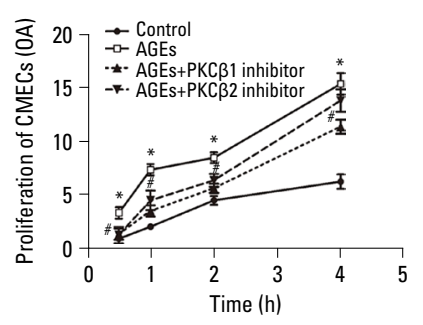

e

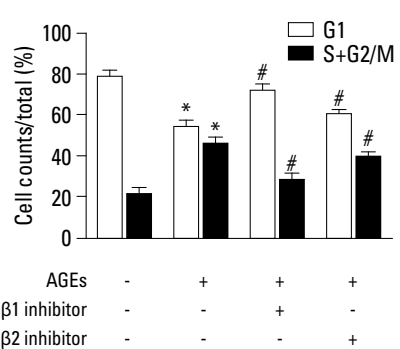

b

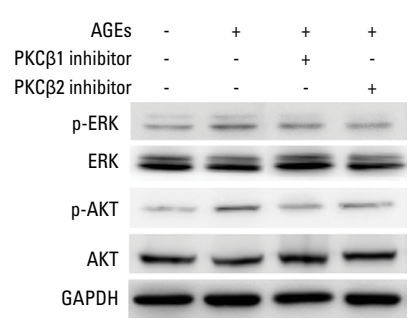

f

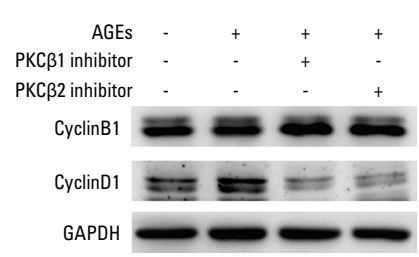

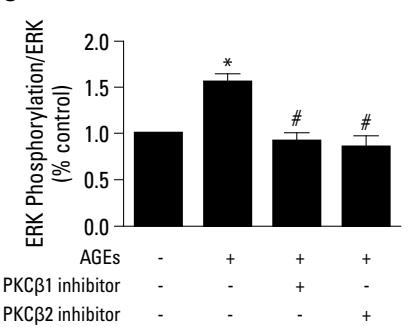

g

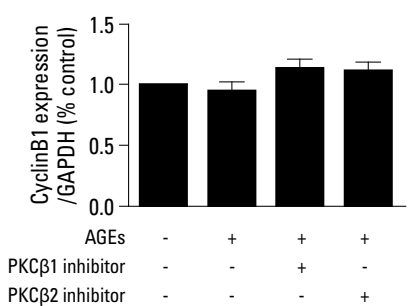

d

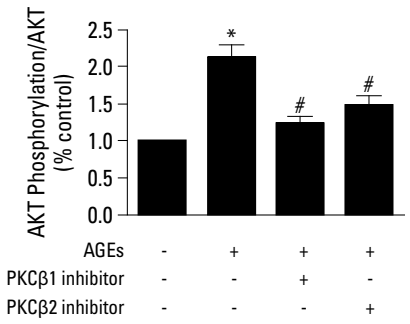

h

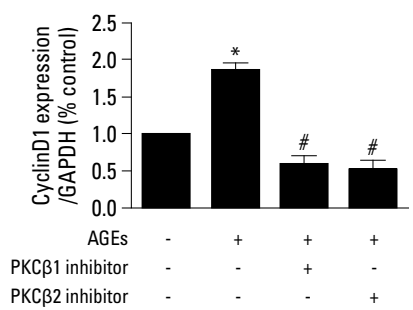

Figure 1. AGEs facilitate the CMECs proliferation, and $P K C \beta$ inhibitor reverses the effect (a) AGEs promote the proliferation of CMECs at $0.5,1,2$, and $4 \mathrm{~h}\left({ }^{*} P<0.05\right.$ vs. control). Both PKC $\beta 1$ and PKC $\beta 2$ inhibitors decrease the proliferation level at $0.5,1,2$, and $4 \mathrm{~h}\left({ }^{*} P<0.05 \mathrm{vs}\right.$. AGEs). (b) Effects of AGEs and PKC $\beta$ inhibitors on proliferation-associated proteins. Protein levels are assessed using the western blot. (c, d) Both the PKC $\beta 1$ inhibitor $(6 \mathrm{nmol} / \mathrm{mL}$ CGP53353) and PKC $\beta 2$ inhibitor $(0.9 \mathrm{nmol} / \mathrm{mL}$ CGP53353) downregulate the phosphorylation of ERK and AKT compared with the AGEs group ( ${ }^{*} P<0.05$ vs. AGEs). (e) Effects of AGEs and PKC $\beta 1 / 2$ inhibitors on cell cycle distributions. Flow shows that the percentage of $A G E s$-treated cells in $\mathrm{G} 1$ phase decreases from $78.5 \%$ to $54.1 \%$, while the percentage in the $\mathrm{S}+\mathrm{G} 2 / \mathrm{M}$ phase increases from $21.5 \%$ to $45.9 \%$ ( $P<0.05$ ). The percentage of $\mathrm{G} 1$ phase cells pretreated with the PKC $\beta 1$ inhibitor $(6.0 \mathrm{nmol} / \mathrm{mL})$ and PKC $\beta 2$ inhibitor $(0.9 \mathrm{nmol} / \mathrm{mL})$ increases from $54.1 \%$ to $71.8 \%$ and $60.3 \%$ ( ${ }^{*} P<0.05$ vs. AGEs). The percentage of cells in the $S+G 2 / M$ phase decreases from $45.9 \%$ to $28.2 \%$ and $39.7 \%$, respectively $\left({ }^{*} P<0.05\right.$ vs. AGEs). ( $f, g, h)$ Effects of AGEs and PKC $\beta 1 / 2$ inhibitors on the cyclin D1/B1 expression by western blotting. AGEs upregulate the expression of cyclin D1 significantly ( ${ }^{*} P<0.05$ vs. control), and no significant effect is observed on cyclin $\mathrm{B} 1$. PKC $\beta 1 / 2$ inhibitors downregulate the expression of cyclin D1 ( ${ }^{*} P<0.05$ vs. AGEs) 
To demonstrate the role of PKC in the proliferation of CMECs, we used PMA to simulate the function of PKC. We treated cells with a PMA ( $50 \mathrm{ng} / \mathrm{mL}$ ), PMA+PKC 31 inhibitor (CGP53353 $6 \mathrm{nmol} /$ $\mathrm{mL}$ ), or $\mathrm{PMA}+\mathrm{PKC} \beta 2$ inhibitor (CGP53353 $0.9 \mathrm{nmol} / \mathrm{mL}$ ). It was found that the PMA/PKC activation could promote the CMECs proliferation independently, while the $\mathrm{PKC} \beta 1 / 2$ inhibition reversed the effect induced by PMA/PKC (Fig. 2a).

The percentage of PMA-treated cells in $\mathrm{G} 1$ phase decreased from $61.8 \%$ to $32.6 \%(p<0.05)$, while cells in the $S+G 2 / M$ phase increased from $38.2 \%$ to $67.4 \%(p<0.05)$. We treated cells with PMA+PKC $\beta 1 / 2$ inhibitors and observed that the percentage of cells in $\mathrm{G} 1$ phase significantly increased from $32.6 \%$ to $80.3 \%$ and $59.4 \%(p<0.05)$, and cells in the $S+G 2 / M$ phase decreased from $67.4 \%$ to $19.7 \%$ and $40.6 \%$ ( $<<0.05$ ) (Fig. $2 b$ ). The results were consistent with those observed for AGEs treatments. Simultaneously, western blotting analysis indicated that PMA/ PKC upregulated the cyclin D1 expression significantly by $140 \%$, while PKC $\beta 1 / 2$ inhibitors reversed the effect induced by PMA/ PKC $(p<0.05)$ (Fig. 2c). The western blotting analysis indicated that PMA/PKC upregulated phosphorylation of ERK $(p<0.05)$, and
PKC $\beta 1 / \beta 2$ inhibitor-treated cells downregulated phosphorylation of ERK (Fig. 2d, 2e).

\section{AGEs and PKC activation both reduced early apoptosis of CMECS}

Flow cytometry revealed that early apoptosis reduced from $5.01 \%$ to $1.83 \%$ in AGEs-treated cells when compared with the control group $(p<0.05)$ (Fig. 3a). However, both the numbers of early apoptotic cells evidently increased after treatment with the PKC $\beta 1 / 2$ inhibition when compared with the AGEs group $(p<0.05)$ (Fig. 3a), which implied that PKC inhibitors could reverse the early apoptosis reduction induced by AGEs.

Furthermore, the expressions of apoptosis-related protein, including survivin, cleaved-caspase3, and B cell lymphoma-2 $(\mathrm{Bcl}-2) / \mathrm{Bcl}-2$ associated $\mathrm{X}$ protein $(\mathrm{Bax})$ were assessed using the western blotting analysis. The expression of survivin was increased by $75.7 \%$, and the expression of cleaved-caspase 3 was decreased by $57.6 \%$ after treatment with AGEs $(p<0.05)$, although the expression of $\mathrm{Bcl}-2$ and Bax were not affected by AGEs (Fig. 3b, 3c, 3d, and 3e). Both PKC $\beta 1 / 2$ inhibitors were able

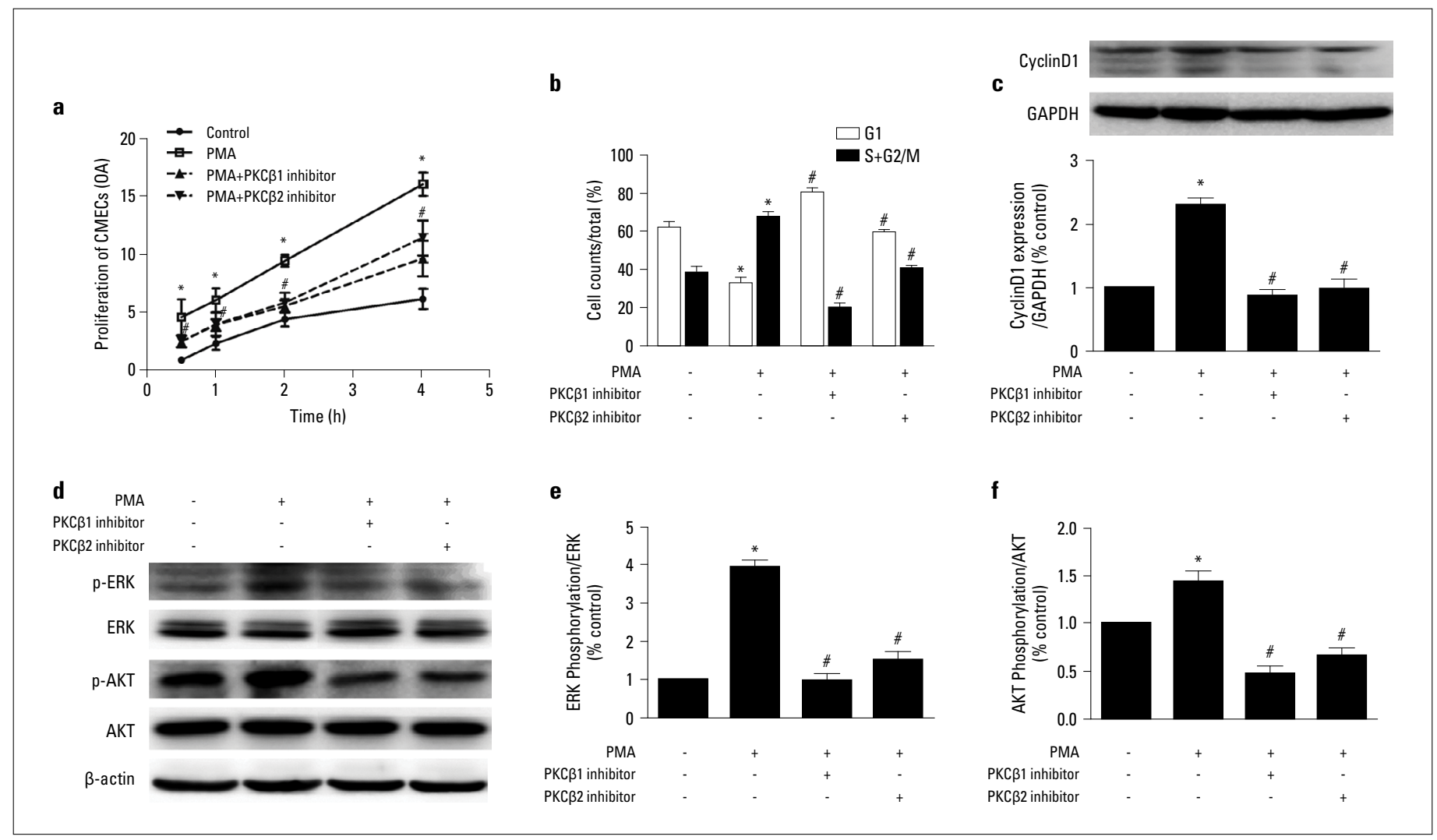

Figure 2. PKC activation promotes CMECs proliferation (a) Effects of PMA on proliferation in CMECs. Compared with control, PMA increases the proliferation of CMECs, and PKC $\beta 1 / 2$ inhibitors reverse these effects induced by PMA ( ${ }^{*} P<0.05$ vs. control; ${ }^{*} P<0.05$ vs. PMA). (b) Effects of PMA and PKC $\beta 1 / 2$ inhibitors on cell cycle distribution. The percentage of PMA-treated cells in $\mathrm{G} 1$ phase decreases from $61.8 \%$ to $32.6 \%$ and cells in the $\mathrm{S}+\mathrm{G} 2 / \mathrm{M}$ phase increase from $38.2 \%$ to $67.4 \%$. The percentage of cells in $\mathrm{G} 1$ phase significantly increases from $32.6 \%$ to $80.3 \%$ and $59.4 \%$ after $\mathrm{PMA}+\mathrm{PKC} \beta 1 / 2$ inhibitors, and cells in the $\mathrm{S}+\mathrm{G} 2 / \mathrm{M}$ phase decrease from $67.4 \%$ to $19.7 \%$ and $40.6 \%$ ( ${ }^{*} P<0.05$ vs. control; ${ }^{*} P<0.05$ vs. $\mathrm{PMA}$ ). (c) Effects of PMA and PKC $\beta 1 / 2$ inhibitors on the cyclin D1 expression. PMA upregulates the cyclin D1 expression by approximately $140 \%$. PKC $\beta 1 / 2$ inhibitors reverse the effect induced by PMA/PKC $\left({ }^{*} P<0.05\right.$ vs. control; ${ }^{*} P<0.05$ vs. PMA). (d, e, f) Effects of PMA and PKC $\beta$ inhibitors on the expression of ERK and AKT. PMA upregulates the phosphorylation of ERK and AKT, and PKC $\beta 1 / 2$ inhibitors decrease the phosphorylation of ERK and AKT compared with the PMA group $\left({ }^{*} P<0.05\right.$ vs. control; ${ }^{*} P<0.05$ vs. PMA) 
to downregulate the expression of survivin and upregulate the expression of cleaved-caspase3 (Fig. 3c, 3d, and 3e), which might indicate that AGEs could reduce early apoptosis of CMECs, while PKC inhibitors CGP53353 could reverse the effect of AGEs in cell apoptosis.

To demonstrate the role of PKC in the apoptosis of CMECs, we also used PMA to simulate the function of PKC. The number of apoptotic cells after pretreatment with PMA was detected. It was found that PMA/PKC significantly decreased the early apoptosis cell counts $(p<0.05)$, which could be reversed by the PKC $\beta 1 / 2$ inhibition $(p<0.05)$ (Fig. 4a). The western blot analysis demonstrated that PMA upregulated the expression of survivin, but downregulated the expression of cleaved-caspase $3(p<0.05)$. Both PKC $\beta 1 / 2$ inhibitors were able to reverse these effects, compared with the PMA group $(\mathrm{p}<0.05)$ (Fig. 4b, 4c, and 4d), which might imply that PMA/PKC could reduce early apoptosis of CMECs.

AGEs upregulated the phosphorylation of PKC $\beta 1$ and PKC $\beta 2$

The RAGE expression was detected using the western blot, and it significantly increased $(p<0.05)$ with the treatment of AGEs (Fig. 5a). AGEs also signific antly promoted the phosphorylation of PKC $\beta 1$ by $121 \%(p<0.05)$ and phosphorylation of $\mathrm{PKC} \beta 2$ by $197 \%$ when compared with the control group $(p<0.05)$ (Fig. $5 d$, 5e, and 5f). These results implied that RAGE and PKC $\beta 1 / 2$ were activated in the AGEs-treated CMECs.

RAGE-siRNA transfection reduced phosphorylation of PKC $\beta 1 / 2$ and obstructed the effects of AGEs on the CMECs proliferation and apoptosis

AGEs promoted the proliferation and reduced the apoptosis of CMECs. To further elucidate whether the PKC pathway participates in the regulation of AGEs-induced proliferation and apoptosis, we used RAGE-siRNA to block the RAGE expression. First, CMECs were cultured in AGEs with $50 \mathrm{nmol} / \mathrm{mL}$ RAGE-siRNA for 24 hours. Then the phosphorylations of $P K C \beta 1 / 2$ were detected. The results indicated that phosphorylations of $\mathrm{PKC} \beta 1$ and $\mathrm{PKC} \beta 2$ were reduced by $33.6 \%$ and $35.4 \%$, respectively, after the siRNA treatment $(p<0.05)$ (Fig. $5 d, 5 e$, and $5 f)$, whereas no changes were observed in the phosphorylation of PKCa (Fig. $5 \mathrm{~g}$, 5h). Furthermore, we found that after the siRNA transfection, the proliferations of CMECs significantly reduced by $58.1 \%, 54.5 \%, 26.9 \%$, and $28 \%$ for $0.5,1,2$, and 4 hours, respectively, compared with AGEs-treated cells $(p<0.05)$ (Fig. $5 b)$, and the number of early apoptotic cells increased $(p<0.05)$ (Fig. $5 c$ ).

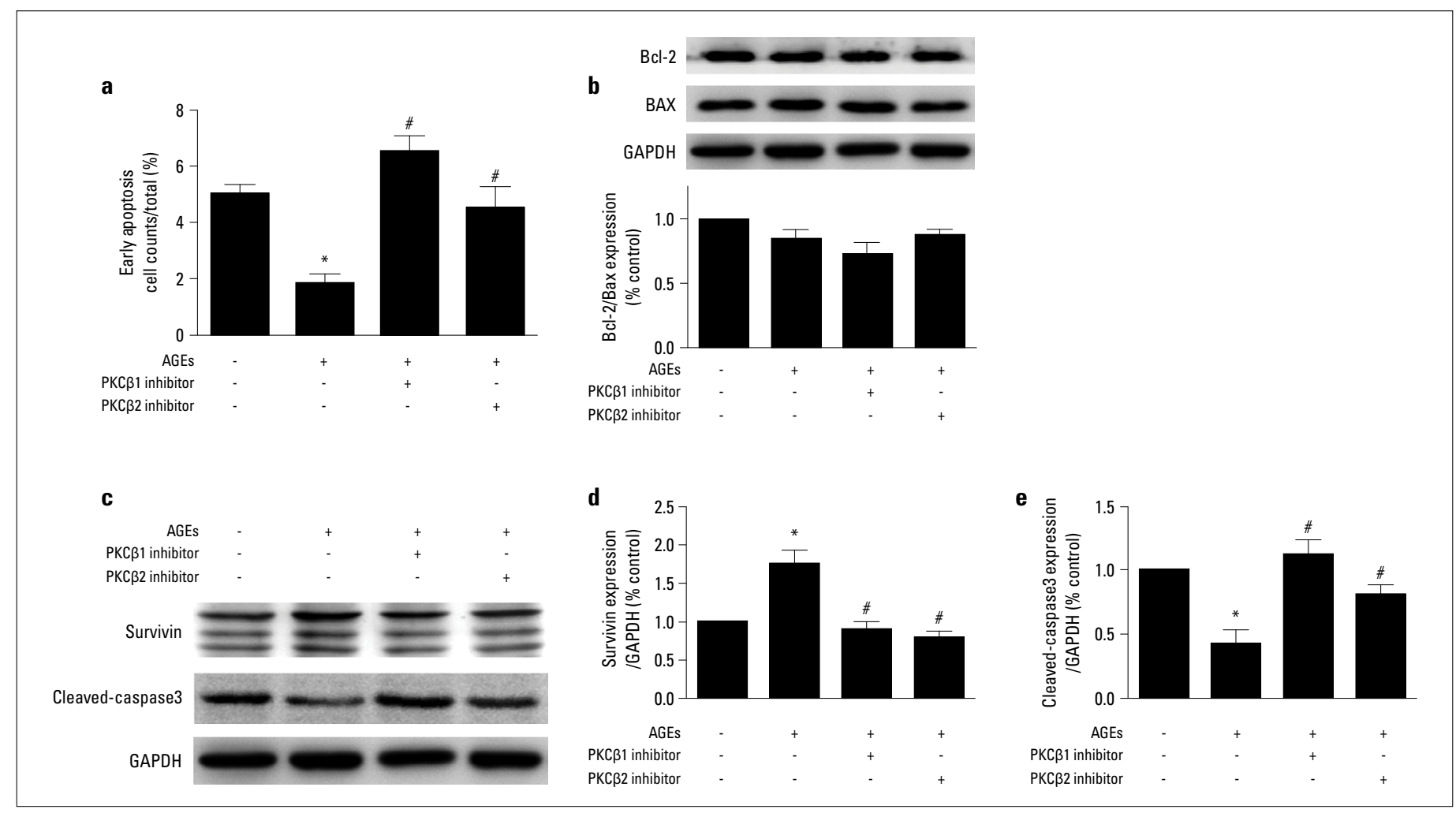

Figure 3. AGEs reduce early apoptosis of CMECs, and the PKC $\beta$ inhibitor reverses the effect (a) Apoptosis is determined using the Annexin V-FITC/PI double staining. Early apoptosis of CMECs is reduced from $5.01 \%$ to $1.83 \%$ in AGEs-treated cells when compared with the control group $\left({ }^{*} P<0.05\right.$ vs. control). The numbers of the early apoptotic cells increase after treatment with the PKC $\beta 1 / 2$ inhibitor when compared with the AGEs group ( ${ }^{P}<0.05$ vs. AGEs). (b, c, d, e) Effects of AGEs and PKC $\beta$ inhibitors on apoptosis-associated proteins. The western blotting analysis showed that the survivin expression is upregulated by $75.7 \%$, and the expression of cleaved-caspase 3 is decreased by $57.6 \%$ after treatment with AGEs $\left({ }^{*} P<0.05\right.$ vs. control). The expression of $\mathrm{Bcl}-2$ and Bax are not affected by AGEs. Both the PKC $\beta 1 / 2$ inhibitors are able to reverse the effect of $A G E s$ in cell apoptosis $\left({ }^{\#} P<0.05\right.$ vs. AGEs) 


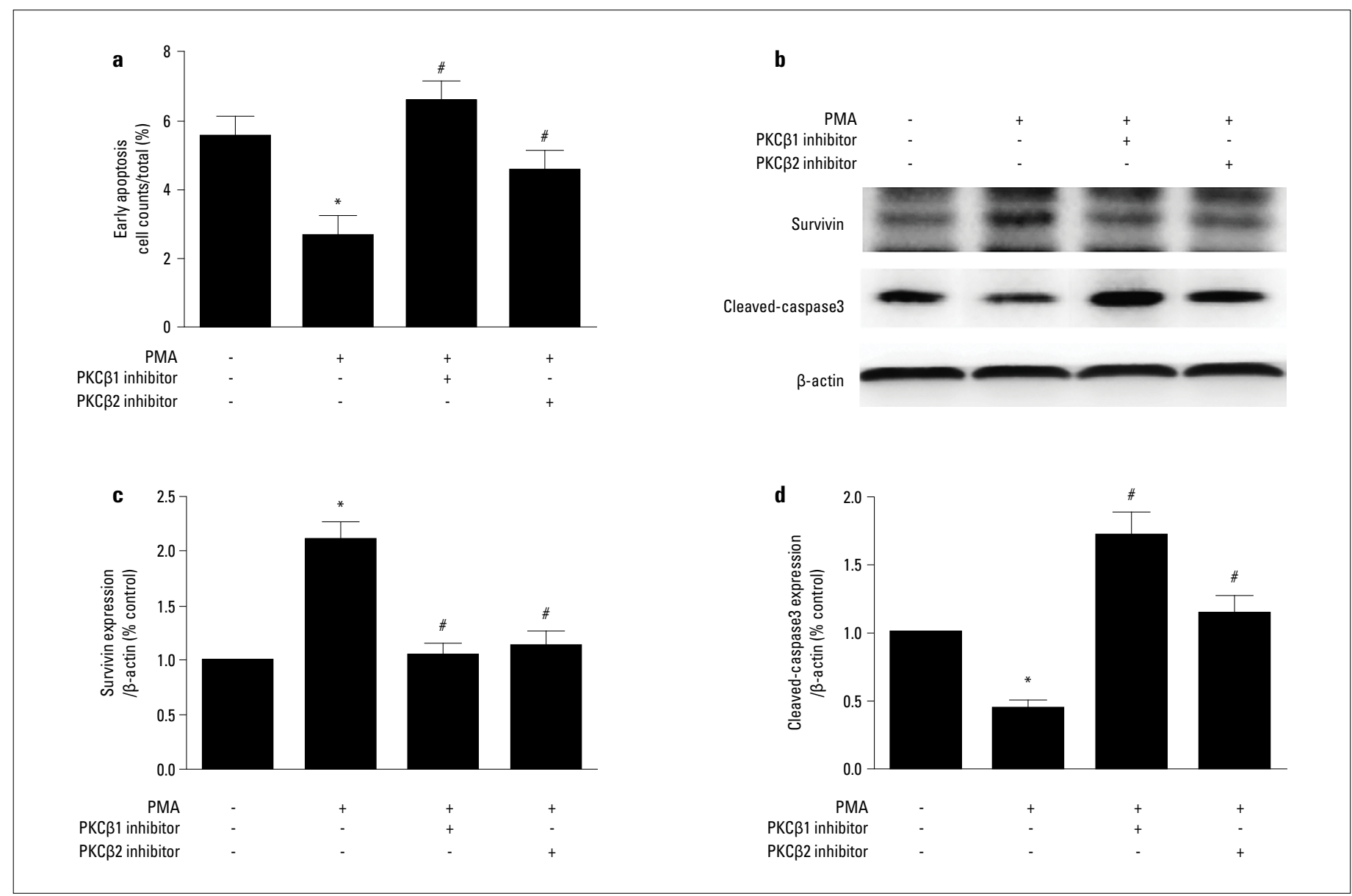

Figure 4. PKC activation reduces early apoptosis of CMECs (a) The number of apoptotic cells after pretreatment with the PKC agonist PMA is detected. PMA/PKC significantly decreases the early apoptosis cell counts from $5.58 \%$ to $2.64 \%\left({ }^{*} P<0.05\right.$ vs. control), which could be reversed by the PKC $\beta 1 / 2$ inhibition ( ${ }^{P} P<0.05$ vs. PMA). (b, $\left.\mathrm{c}, \mathrm{d}\right)$ The western blot analysis demonstrated that PMA upregulates the expression of survivin, but downregulates the expression of cleaved-caspase $3\left({ }^{*} P<0.05\right.$ vs. control). Both $\mathrm{PKC} \beta 1 / 2$ inhibitors are able to reverse these effects $\left({ }^{\sharp} P<0.05\right.$ vs. PMA)

\section{Discussion}

There are two types of vascular diseases in diabetes. One is microangiopathy, which mainly affects capillaries and arterioles and is unique to diabetes, and the other is macroangiopathy, which is similar to non-diabetic atherosclerosis (3). Micro vessels are the most widely distributed blood vessel connecting the arterioles and venules. Although their largest diameter is only $100 \mu \mathrm{m}$, their wall is highly permeable, facilitating a sufficient material exchange between blood and tissues (19). Myocardial tissue has an extremely rich capillary network. The microcirculation of the heart is composed of blood circulation between its arterioles and venules, which can affect myocardial perfusion (20).

At present, coronary angiography and percutaneous coronary intervention are preferable in the clinical treatment of macrovascular diseases. However, completely effective treatments for microvascular diseases have not been found, which leads to clinical presence of cardiac patients with persisting and progressing symptoms, although they have received stan- dard care. Therefore, more researches should focus on microangiopathy.

CMECs contribute to the pathogenesis of cardiac microvascular diseases and have different specific functions compared with other vascular endothelial cells. Researches have supported the involvement of AGEs in the pathogenesis of diabetic vascular complications $(10,21)$. However, the effects of AGEs on CMECs, especially the relationship with the $\operatorname{PKC} \beta$ signaling pathway, remain unclear.

Some studies showed that AGEs inhibited proliferation and promoted apoptosis in endothelial progenitor cells (22), mesangial cells (23), and acute myeloid leukemia cells (24), and others found that the activation of RAGE facilitated proliferation and reduced apoptosis in pulmonary artery smooth muscle cells (25). Those controversial outcomes suggested that AGEs might selectively act on several types of cells under different pathophysiological conditions. In the present study, we found that AGEs facilitated proliferation and reduced early apoptosis of CMECs, and all these effects could be reversed by PKC $\beta 1 / 2$ inhibitors. We subsequently confirmed that PKC could also in- 


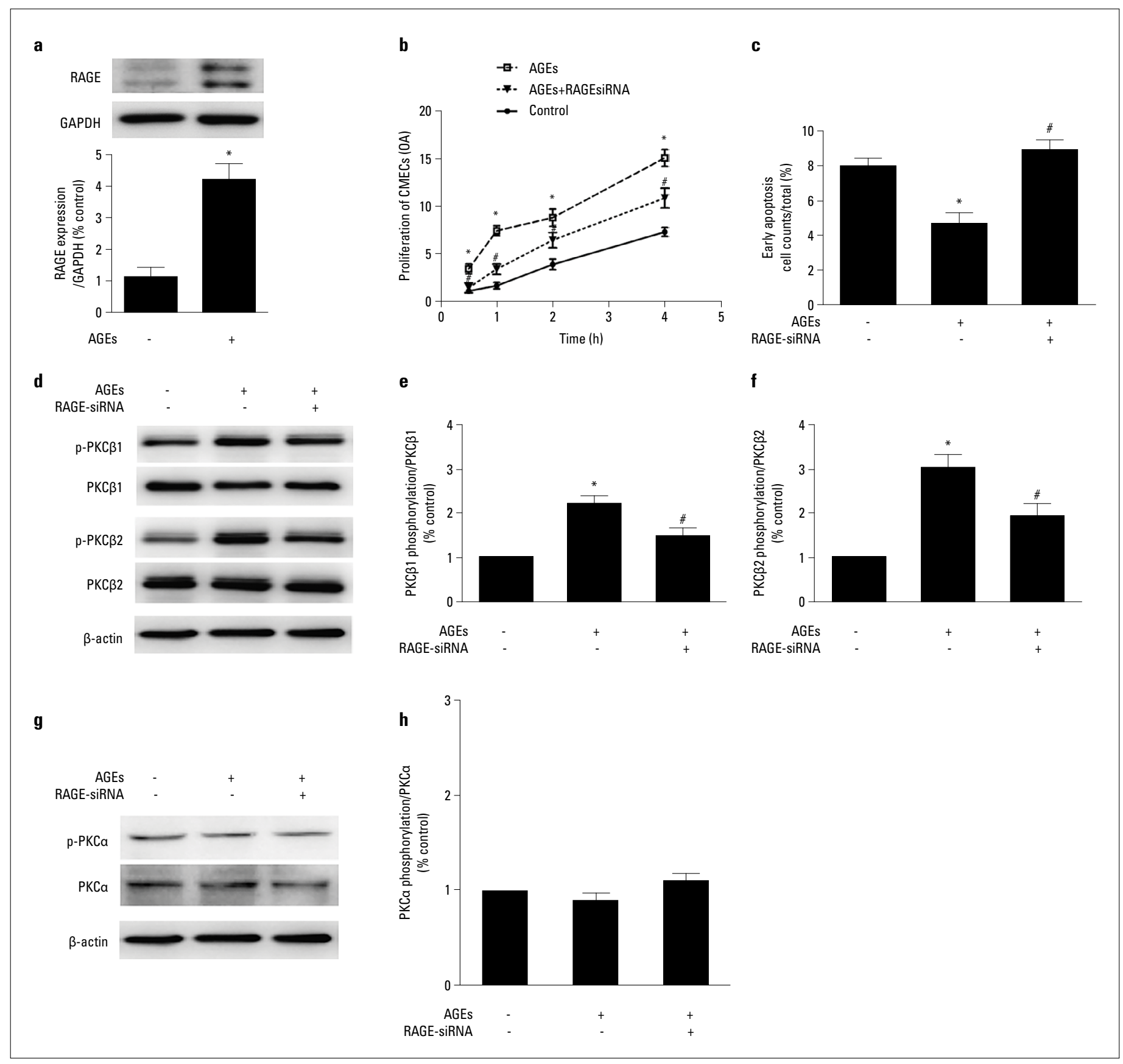

Figure 5. Effect of AGEs on PKC (a) Effects of AGEs on RAGE protein expression. Protein levels were assessed using the western blot. AGEs upregulates the RAGE expression. The significance of differences is as indicated $\left({ }^{*} P<0.05\right)$. (b) After siRNA transfections, the proliferation of CMECs is reduced by $58.1 \%, 54.5 \%, 26.9 \%$, and $28 \%$ at $0.5,1,2$, and $4 \mathrm{~h}$ respectively, compared with AGEs-treated cells ( ${ }^{*} P<0.05$ vs. AGEs). (c) After siRNA transfections, the number of early apoptosis cells significantly increases versus AGEs-treated group ( ${ }^{*} P<0.05$ vs. AGEs). (d, e, f) Phosphorylation of PKC $\beta 1, P K C \beta 2$ induced by AGEs in CMECs and relative PKC $\beta 1 / 2$ phosphorylation levels after RAGE-siRNA transfections. AGEs enhance phosphorylation of $\mathrm{PKC} \beta 1 / 2\left({ }^{*} P<0.05\right.$ vs. control), and phosphorylation of PKC $\beta 1 / 2$ is significantly downregulated by RAGE-siRNA transfection ( ${ }^{P} P<0.05$ vs. AGEs). (g, h) Phosphorylation of PKCa in AGEs-treated CMECs and relative PKCa phosphorylation levels after RAGEsiRNA transfections. There is no significant difference in phosphorylation of PKCa ( $P>0.05$ vs. control)

dependently regulate the phenotype of CMECs, indicating the AGEs may work on CMECs through PKC $\beta$. Hence, we explored further and verified that AGEs indeed upregulated phosphorylation of $P K C \beta 1$ and $P K C \beta 2$, and RAGE-siRNA transfection reduced phosphorylation of PKC $\beta 1 / 2$ and obstructed the effects of AGEs on CMECs.
PKC is a family of protein kinase enzymes involved in controlling the function of other proteins through the phosphorylation of hydroxyl groups of serine and threonine amino acid residues on these proteins. PKC enzymes are activated by signals such as increases in the diacylglycerol (DAG) concentration or calcium ions. Previous studies indicated that diabetes led to vas- 
cular DAG accumulation and ensuing PKC activation, causing a variety of cardiovascular complications (26). It was reported that the PKC activation by hyperglycemia was likely to be responsible for specific vascular pathologies such as endothelial cells and smooth muscle cells dysfunction, extracellular matrix synthesis and fibrosis, monocyte activation, and vascular insulin dysfunction (11). Moreover, the PKC $\beta$ inhibition might represent a novel therapy in the prevention of diabetic cardiovascular complications through attenuating diastolic dysfunction, myocyte hypertrophy, collagen deposition, and preserving cardiac contractility $(27,28)$. It was also reported that the РКС $\beta$ inhibition reduced the cardiac microvascular barrier impairment (14). All the above findings supported the importance of PKC $\beta$ in myocardial cells and endotheliocyte.

As the cell cycle was related to proliferation, the effects of AGEs on cell cycle distribution were also examined. Results showed that AGEs accelerated the CMECs from G1 phase to the $\mathrm{S}+\mathrm{G} 2 / \mathrm{M}$ phase, which resulted in elevated DNA synthesis (29). At the same time, the expression of cyclin D1, which was the crucial checkpoint protein from $\mathrm{G} 1$ to $\mathrm{S}$ phase, was upregulated by AGEs. The result was reversed by PKC $\beta 1 / 2$ inhibitors, which was in agreement with the effects of PMA/PKC. Thus, we inferred that AGEs promote the proliferation of CMECs through the activation of the $\mathrm{PKC} \beta$ pathway and subsequent transcriptional activation of cyclin D1.

RAGE can be found on many cells, including endothelial cells, smooth muscle, and cells of the immune system. When binding with AGEs, it contributes to diabetes-related chronic inflammatory diseases and is associated with the progression of cardiovascular diseases and diabetes (30). The AGE/RAGE interaction observed in diabetes stimulates endothelial pro-inflammatory gene expression and reactive oxygen species (ROS) production in a nicotinamide adenine dinucleotide phosphate (NADPH)oxidase dependent manner (31), which might contribute to endothelial dysfunction. AGE/RAGE also plays a critical role in the chronic activation of the immune inflammatory processes that accelerate atherosclerosis in diabetes (32). In our study, we demonstrated that AGE/RAGE played a critical role in the CMECs proliferation and apoptosis in diabetic cardiomyopathy. By specific RAGE-siRNA transfection in CMECs, we successfully reduced the phosphorylation of $\mathrm{PKC} \beta 1 / 2$ and obstructed the process of CMECs' proliferation and apoptosis. These findings suggested that the AGEs-RAGE-PKC $\beta$ was one of the mechanisms in the pathophysiological process of CMECs' proliferation and apoptosis and provided a novel insight into the pathogenesis of diabetic cardiomyopathy.

PKC signaling pathways are activated in diabetic cardiomyopathy. To date, $\approx 15$ isoforms of PKC have been described in humans. PKCa, $\beta, \varepsilon, \theta$, and $\delta$ isoforms have been proposed to be involved in the development of diabetic cardiac hypertrophy $(5$, $33,34)$. PKCa is the predominant member among the different PKC isozymes expressed in the cardiac tissue (35-38). PKCa is increased in human cardiac pathology $(36,39)$ and during the transition to heart failure (40). It plays crucial roles in cardiomyocyte hypertrophy, and it is an important regulator of muscle contractility $(41,42)$.

To exclude the possible contribution of other isoforms for the signaling mechanism, we also investigated PKCa in addition to PKC $\beta$. It showed that AGEs upregulated the expression of RAGE and phosphorylated PKC $\beta 1$ and $P K C \beta 2$, but not phosphorylated PKCa. Although PKCa is involved in the development of diabetic cardiomyopathy, our results implied that AGEs facilitate proliferation and reduce early apoptosis of cardiac microvascular endothelial cell via PKC $\beta$, but not the PKCa signaling pathway. Although AEGs do not act through PKCa, this does not affect other PKCa physiological effects in cardiomyopathy mentioned and discussed above.

\section{Study limitations}

Although this research did not provide evidence in vivo to support the hypotheses, it is still pioneering, and we can clarify that AGEs can regulate CMEC function through the $\mathrm{PKC} \beta$ signaling pathway in diabetes.

\section{Conclusion}

Our findings demonstrated that AGEs facilitated proliferation and reduced early apoptosis of CMECs through the activation of the $\operatorname{PKC} \beta$ signaling pathway, which might be related to the pathogenesis of diabetic cardiomyopathy.

Acknowledgements: We are grateful to all members of Professor Fu Guosheng's team for many valuable discussions and thoughtful critique of the manuscript.

Funding: This work was funded by the National Natural Science Foundation of China (81700213), Natural Science Foundation of Zhejiang Province (LY18H020007), and Medical and Health Technology Program of Zhejiang Province (2018263306).

Conflict of interest: None declared.

Peer-review: Externally peer-reviewed.

Authorship contributions: Concept - J.Z., G.F., W.Z.; Design - Y.L., J.Z., W.Z.; Supervision - G.F., W.Z.; Funding - Y.L.; Materials - Y.L., J.Z., M.W.; Data collection and/or processing - Y.L., J.Z., M.W.; Analysis and/ or interpretation - Y.L., J.Z., M.W.; Literature search - Y.L., J.Z., M.W.; Writing - Y.L., J.Z.; Critical review - G.F., W.Z.

\section{References}

1. Falcão-Pires I, Leite-Moreira AF. Diabetic cardiomyopathy: understanding the molecular and cellular basis to progress in diagnosis and treatment. Heart Fail Rev 2012; 17: 325-44. [CrossRef]

2. Adameova A, Dhalla NS. Role of microangiopathy in diabetic cardiomyopathy. Heart Fail Rev 2014; 19: 25-33. [CrossRef] 
3. Miki T, Yuda S, Kouzu H, Miura T. Diabetic cardiomyopathy: pathophysiology and clinical features. Heart Fail Rev 2013; 18: 149-66.

4. Mizamtsidi M, Paschou SA, Grapsa J, Vryonidou A. Diabetic cardiomyopathy: a clinical entity or a cluster of molecular heart changes? Eur J Clin Invest 2016; 46: 947-53. [CrossRef]

5. Jia G, Hill MA, Sowers JR. Diabetic Cardiomyopathy: An Update of Mechanisms Contributing to This Clinical Entity. Circ Res 2018; 122: 624-38. [CrossRef]

6. Yin Z, Fan L, Wei L, Gao H, Zhang R, Tao L, et al. FTY720 protects cardiac microvessels of diabetes: a critical role of $\mathrm{S} 1 \mathrm{P} 1 / 3$ in diabetic heart disease. PLoS One 2012; 7: e42900. [CrossRef]

7. Jaap AJ, Tooke JE. Pathophysiology of microvascular disease in non-insulin-dependent diabetes. Clin Sci (Lond) 1995; 89: 3-12.

8. Yamagishi S, Fukami K, Matsui T. Crosstalk between advanced glycation end products (AGEs)-receptor RAGE axis and dipeptidyl peptidase-4-incretin system in diabetic vascular complications. Cardiovasc Diabetol 2015; 14: 2. [CrossRef]

9. Goldin A, Beckman JA, Schmidt AM, Creager MA. Advanced glycation end products: sparking the development of diabetic vascular injury. Circulation 2006; 114: 597-605. [CrossRef]

10. Liu Y, Ma Y, Wang R, Xia C, Zhang R, Lian K, et al. Advanced glycation end products accelerate ischemia/reperfusion injury through receptor of advanced end product/nitrative thioredoxin inactivation in cardiac microvascular endothelial cells. Antioxid Redox Signal 2011; 15: 1769-78. [CrossRef]

11. Geraldes $P$, King GL. Activation of protein kinase $C$ isoforms and its impact on diabetic complications. Circ Res 2010; 106: 1319-31.

12. Koya D, King GL. Protein kinase $C$ activation and the development of diabetic complications. Diabetes 1998; 47: 859-66. [CrossRef]

13. Wei L, Sun D, Yin Z, Yuan Y, Hwang A, Zhang Y, et al. A PKC- $\beta$ inhibitor protects against cardiac microvascular ischemia reperfusion injury in diabetic rats. Apoptosis 2010; 15: 488-98. [CrossRef]

14. Yuan SY, Ustinova EE, Wu MH, Tinsley JH, Xu W, Korompai FL, et al. Protein kinase $C$ activation contributes to microvascular barrier dysfunction in the heart at early stages of diabetes. Circ Res 2000; 87: 412-7. [CrossRef]

15. Weng LQ, Zhang WB, Ye Y, Yin PP, Yuan J, Wang XX, et al. Aliskiren ameliorates pressure overload-induced heart hypertrophy and fibrosis in mice. Acta Pharmacol Sin 2014; 35: 1005-14. [CrossRef]

16. Liu Y, Jin J, Qiao S, Lei S, Liao S, Ge ZD, et al. Inhibition of PKC $\beta 2$ overexpression ameliorates myocardial ischaemia/reperfusion injury in diabetic rats via restoring caveolin-3/Akt signaling. Clin Sci (Lond) 2015; 129: 331-44. [CrossRef]

17. Li L, Rui X, Liu T, Xu G, He S. Effect of heparin-derived oligosaccharide on vascular smooth muscle cell proliferation and the signal transduction mechanisms involved. Cardiovasc Drugs Ther 2012; 26: 479-88. [CrossRef]

18. Jin C, Zhao Y, Yu L, Xu S, Fu G. MicroRNA-21 mediates the rapamycin-induced suppression of endothelial proliferation and migration. FEBS Lett 2013; 587: 378-85. [CrossRef]

19. Dejana E. Endothelial cell-cell junctions: happy together. Nat Rev Mol Cell Biol 2004; 5: 261-70. [CrossRef]

20. Uchida $Y$, Ichimiya S, Ishii H, Kanashiro M, Watanabe J, Yoshikawa $D$, et al. Impact of metabolic syndrome on various aspects of microcirculation and major adverse cardiac events in patients with ST-segment elevation myocardial infarction. Circ J 2012; 76 : 1972-9. [CrossRef]

21. Ishibashi Y, Matsui T, Maeda S, Higashimoto Y, Yamagishi S. Advanced glycation end products evoke endothelial cell damage by stimulating soluble dipeptidyl peptidase-4 production and its in- teraction with mannose 6-phosphate/insulin-like growth factor II receptor. Cardiovasc Diabetol 2013; 12: 125. [CrossRef]

22. Chen J, Song M, Yu S, Gao P, Yu Y, Wang H, et al. Advanced glycation endproducts alter functions and promote apoptosis in endothelial progenitor cells through receptor for advanced glycation endproducts mediate overpression of cell oxidant stress. Mol Cell Biochem 2010; 335: 137-46. [CrossRef]

23. Yamagishi S, Inagaki Y, Okamoto T, Amano S, Koga K, Takeuchi M, et al. Advanced glycation end product-induced apoptosis and overexpression of vascular endothelial growth factor and monocyte chemoattractant protein-1 in human-cultured mesangial cells. J Biol Chem 2002; 277: 20309-15. [CrossRef]

24. Kim JY, Park HK, Yoon JS, Kim SJ, Kim ES, Ahn KS, et al. Advanced glycation end product (AGE)-induced proliferation of HEL cells via receptor for AGE-related signal pathways. Int J Oncol 2008; 33: 493501.

25. Meloche J, Courchesne A, Barrier M, Carter S, Bisserier M, Paulin $\mathrm{R}$, et al. Critical role for the advanced glycation end-products receptor in pulmonary arterial hypertension etiology. J Am Heart Assoc 2013; 2: e005157. [CrossRef]

26. Idris I, Gray S, Donnelly R. Protein kinase C activation: isozymespecific effects on metabolism and cardiovascular complications in diabetes. Diabetologia 2001; 44: 659-73. [CrossRef]

27. Connelly KA, Kelly DJ, Zhang Y, Prior DL, Advani A, Cox AJ, et al. Inhibition of protein kinase $C-\beta$ by ruboxistaurin preserves cardiac function and reduces extracellular matrix production in diabetic cardiomyopathy. Circ Heart Fail 2009; 2: 129-37. [CrossRef]

28. Idris I, Donnelly R. Protein kinase $C \beta$ inhibition: a novel therapeutic strategy for diabetic microangiopathy. Diab Vasc Dis Res 2006: 1728. [CrossRef]

29. Franke S, Sommer M, Rüster C, Bondeva T, Marticke J, Hofmann G, et al. Advanced glycation end products induce cell cycle arrest and proinflammatory changes in osteoarthritic fibroblast-like synovial cells. Arthritis Res Ther 2009; 11: R136. [CrossRef]

30. Metz VV, Kojro E, Rat D, Postina R. Induction of RAGE shedding by activation of $G$ protein-coupled receptors. PLoS One 2012; 7: e41823. [CrossRef]

31. Piga R, Naito Y, Kokura S, Handa O, Yoshikawa T. Short-term high glucose exposure induces monocyte-endothelial cells adhesion and transmigration by increasing VCAM-1 and MCP-1 expression in human aortic endothelial cells. Atherosclerosis 2007; 193: 328-34.

32. Akirav EM, Preston-Hurlburt P, Garyu J, Henegariu 0, Clynes R, Schmidt AM, et al. RAGE expression in human T cells: a link between environmental factors and adaptive immune responses. PLoS One 2012; 7: e34698. [CrossRef]

33. Lei S, Li H, Xu J, Liu Y, Gao X, Wang J, et al. Hyperglycemia-induced protein kinase $C$ beta2 activation induces diastolic cardiac dysfunction in diabetic rats by impairing caveolin-3 expression and Akt/eNOS signaling. Diabetes 2013; 62: 2318-28. [CrossRef]

34. Li Z, Abdullah CS, Jin ZO. Inhibition of PKC-theta preserves cardiac function and reduces fibrosis in streptozotocin-induced diabetic cardiomyopathy. Br J Pharmacol 2014; 171: 2913-24. [CrossRef]

35. Rohde S, Sabri A, Kamasamudran R, Steinberg SF. The alpha (1)-adrenoceptor subtype- and protein kinase $C$ isoform-dependence of Norepinephrine's actions in cardiomyocytes. J Mol Cell Cardiol 2000; 32: 1193-209. [CrossRef]

36. Hambleton M, Hahn H, Pleger ST, Kuhn MC, Klevitsky R, Carr AN, et al. Pharmacological- and gene therapy-based inhibition of protein kinase Calpha/beta enhances cardiac contractility and attenuates heart failure. Circulation 2006; 114: 574-82. [CrossRef] 
37. Simonis G, Briem SK, Schoen SP, Bock M, Marquetant R, Strasser RH. Protein kinase $C$ in the human heart: differential regulation of the isoforms in aortic stenosis or dilated cardiomyopathy. Mol Cell Biochem 2007; 305: 103-11. [CrossRef]

38. Marrocco V, Bogomolovas J, Ehler E, Dos Remedios CG, Yu J, Gao $C$, et al. PKC and PKN in heart disease. J Mol Cell Cardiol 2019; 128: 212-26. [CrossRef]

39. Bowling N, Walsh RA, Song G, Estridge T, Sandusky GE, Fouts RL, et al. Increased protein kinase $\mathrm{C}$ activity and expression of $\mathrm{Ca} 2+$-sensitive isoforms in the failing human heart. Circulation 1999; 99: 384-91.
40. Bayer AL, Heidkamp MC, Patel N, Porter M, Engman S, Samarel AM. Alterations in protein kinase $C$ isoenzyme expression and autophosphorylation during the progression of pressure overload-induced left ventricular hypertrophy. Mol Cell Biochem 2003; 242: 145-52. [CrossRef]

41. Braz JC, Gregory K, Pathak A, Zhao W, Sahin B, Klevitsky R, et al. PKC-alpha regulates cardiac contractility and propensity toward heart failure. Nat Med 2004; 10: 248-54. [CrossRef]

42. Yang L, Liu G, Zakharov SI, Morrow JP, Rybin V0, Steinberg SF, et al. Ser1928 is a common site for Cav1.2 phosphorylation by protein kinase $C$ isoforms. J Biol Chem 2005; 280: 207-14. [CrossRef] 